\title{
HUBUNGAN USIA DAN JARAK KEHAMILAN DENGAN KEJADIAN ANEMIA KLINIS SELAMA KEHAMILAN
}

\author{
Vevi Gusnidarsih ${ }^{1}$ \\ ${ }^{1)}$ Akademi Kebidanan Manna Bengkulu Selatan \\ richiekhenzo@gmail.com
}

\begin{abstract}
ABSTRAK
Ibu hamil dengan anemia harus mendapatkan pelayanan kesehatan yang tepat dan penanganan serius dari semua pihak karena anemia berpotensi membahayakan keselamatan ibu dan bayi. Angka kejadian anemia selama kehamilan di Indonesia pada tahun 2013 sebesar $37,1 \%$ dan meningkat menjadi $48,9 \%$ pada tahun 2018. Salah satu penyebab kejadian anemia klinis selama kehamilan adalah usia dan jarak kehamilan. Penelitian ini menggunakan metode survei analitik dengan pendekatan cross sectional. Tujuan penelitian ini untuk mengetahui hubungan usia dan jarak kehamilan dengan kejadian anemia klinis selama kehamilan di wilayah kerja Puskesmas Talang Randai. Populasi dalam penelitian ini adalah semua ibu hamil periode Februari - Maret 2019 berjumlah 58 orang. Analisis data menggunakan uji chi-square. Hasil penelitian menunjukkan terdapat hubungan antara usia ( $\rho$-value: 0,002$)$ dan jarak kehamilan ( $\rho$-value: 0,003$)$ dengan kejadian anemia klinis selama kehamilan.
\end{abstract}

Kata kunci : anemia, jarak kehamilan, usia

\begin{abstract}
Pregnant women who have anemia must get proper health care and serious handling from all stakeholders, because anemia have potential dangerous to mothers and babies safety. The incidence of anemia during pregnancy in Indonesia in 2013 was 37.1\% and increased to $48.9 \%$ in 2018. One cause of the incidence of clinical anemia during pregnancy is the age and distance of pregnancy. This study uses analytic methods using cross sectional approval. The aim is to determine the relationship between age and pregnancy distance with clinical anemia during pregnancy in the Talang Randai Public Health Center. The population in this study were all pregnant women from February to March 2019, requesting 58 people. Data analysis using chi-square test. The results of the study show the relationship between age ( $\rho$-value: 0.002) and pregnancy distance ( $\rho$-value: 0.003$)$ with the incidence of clinical anemia during pregnancy.
\end{abstract}

Keywords: anemia, age, pregnancy distance 


\section{PENDAHULUAN}

Anemia yang terjadi selama kehamilan dapat berpotensi menyebabkan kematian ibu. Angka Kematian Ibu (AKI) di Indonesia menurut Survei Angka Sensus (Suvas) pada tahun 2015 adalah 305 per $100.000 \mathrm{KH}$ (Kemenkes RI 2019). Ibu hamil yang mengalami anemia di dunia masih sangat tinggi. Berdasarkan data dari World Health Organization (WHO), angka kejadian anemia pada ibu hamil adalah sebesar 41,8\%. Di Indonesia terjadi peningkatan angka kejadian anemia pada kehamilan yang semula pada tahun 2013 sebesar $37,1 \%$ meningkat menjadi 48,9\% pada tahun 2018 (Riskesdas 2018).

Ibu hamil mengalami anemia apabila setelah diperiksa terjadi penurunan kadar hemoglobin. Kadar hemoglobin ibu hamil dikategorikan mengalami anemia adalah apabila kehamilan trimester pertama dan trimester ketiga kurang dari 11 gram $\%$, atau sebesar 10,5 gram \% pada kehamilan trimester kedua (Saifuddin AB 2011).

Anemia pada kehamilan dapat membahayakan ibu ataupun janin yang dikandung, sehingga anemia dalam kehamilan disebut "potential danger to mother and child". Akibat yang dapat terjadi apabila ibu hamil mengalami anemia antara lain pada saat kehamilan dapat terjadi keguguran, partus prematurus, terhambatnya tumbuh kembang janin, perdarahan ante partum. Pada saat persalinan dapat menyebabkan kejadian Ketuban Pecah Dini (KPD), gangguan his sampai dengan partus terlantar. Pada masa nifas dapat menyebabkan perdarahan post partum, infeksi masa nifas, dan produksi air susu berkurang (Setiawati et al. 2014).

Kementerian Kesehatan bekerja sama dengan BKKBN mengeluarkan sebuah keputusan untuk mengatasi masalah tersebut. Keputusan itu dikenal dengan 4 Jangan dan 3 Terlambat. Adapun 4 jangan tersebut adalah pertama jangan hamil terlalu dekat, kedua jangan sering melahirkan, ketiga jangan terlalu dekat jarak anak, dan keempat jangan hamil dan melahirkan dengan usia terlalu tua. Keputusan 4 jangan yang dikeluarkan oleh pemerintah ini dilakukan untuk mencegah terjadinya 3 terlambat yaitu terlambat mendeteksi kalainan ibu hamil, terlambat ke fasilitas kesehatan, dan terlambat mendapat penanganan kesehatan (Faqih M 2013).

Jumlah ibu hamil di Kabupaten Bengkulu Selatan pada tahun pada tahun 2018 dari sebanyak 3.016 ibu hamil dan terdapat 445 ibu hamil beresiko. Dari 14 puskesmas yang ada di Bengkulu Selatan diperoleh hasil bahwa Puskesmas Talang Randai termasuk puskesmas dengan risiko kehamilan tertinggi sebanyak 94,64 \% (DINKES Kabupaten Bengkulu Selatan 2018).

Berdasarkan data di atas peneliti tertarik untuk meneliti tentang "Hubungan usia dan jarak kehamilan dengan kejadian anemia klinis selama kehamilan di Wilayah Kerja Puskesmas Talang Randai Kabupaten Bengkulu Selatan”.

\section{METODOLOGI}

Metode dalam penelitian ini menggunakan metode survei analitik dengan menggunakan pendekatan cross sectional. Tempat penelitian ini Wilayah Kerja Puskesmas Talang Randai Kabupaten Bengkulu Selatan. Populasi penelitian ini semua ibu hamil dari bulan Februari - Maret 2019 berjumlah 58 ibu hamil. Sampel dalam penelitian ini diperoleh menggunakan teknik total sampling. Instrumen penelitian menggunakan format pengumpulan data (check list), dianalisis dengan menggunakan analisis univariat dan bivariat. 
HASIL

1. Analisis Univariat

Tabel 1. Distribusi Frekuensi Usia Ibu di Wilayah Kerja Puskesmas Talang Randai Kabupaten Bengkulu Selatan

\begin{tabular}{lcc}
\hline \multicolumn{1}{c}{ Kategori Usia } & n & \% \\
\hline $\begin{array}{l}\text { Beresiko } \\
(<20 \&>35 \text { tahun })\end{array}$ & 34 & 58,6 \\
$\begin{array}{l}\text { Tidak Beresiko } \\
(20-35 \text { tahun })\end{array}$ & 24 & 41,4 \\
\hline \multicolumn{1}{c}{ Jumlah } & $\mathbf{5 8}$ & $\mathbf{1 0 0 , 0}$ \\
\hline
\end{tabular}

Berdasarkan tabel 1 di atas dapat diketahui bahwa separuh responden tersebut berusia beresiko $(<20 \&>35$ tahun) yaitu sebanyak 34 responden $(58,6 \%)$.

Tabel 2. Distribusi Frekuensi Jarak

Kehamilan di Wilayah Kerja Puskesmas Talang Randai Kabupaten Bengkulu Selatan

\begin{tabular}{lcc}
\hline Kategori Jarak Kehamilan & n & \% \\
\hline $\begin{array}{l}\text { Beresiko } \\
(<2 \text { tahun })\end{array}$ & 29 & 50,0 \\
\hline
\end{tabular}

\begin{tabular}{lcc}
\hline Kategori Jarak Kehamilan & n & \% \\
\hline $\begin{array}{l}\text { Tidak Beresiko } \\
(2-5 \text { tahun })\end{array}$ & 27 & 46,6 \\
\hline \multicolumn{1}{c}{ Jumlah } & $\mathbf{5 6}$ & $\mathbf{1 0 0 , 0}$ \\
\hline
\end{tabular}

Berdasarkan tabel 2 di atas dapat diketahui bahwa separuh responden tersebut dengan jarak kehamilan beresiko $(<2$ tahun) yaitu sebanyak 29 responden (50,0\%).

Tabel 3. Distribusi Frekuensi Kejadian Anemia Klinis Selama Kehamilan di Wilayah Kerja Puskesmas Talang Randai Kabupaten Bengkulu Selatan

\begin{tabular}{|c|c|c|}
\hline $\begin{array}{c}\text { Kategori Kejadian Anemia } \\
\text { Klinis }\end{array}$ & $\mathbf{n}$ & $\%$ \\
\hline Anemia & 31 & 53,4 \\
\hline Tidak Anemia & 27 & 46,6 \\
\hline Jumlah & 58 & 100,0 \\
\hline \multicolumn{3}{|c|}{$\begin{array}{l}\text { Berdasarkan tabel } 3 \text { di atas dapat } \\
\text { hui bahwa sebagian besar responden } \\
\text { ut mengalami kejadian anemia klinis } \\
\text { a kehamilan yaitu sebanyak } 31 \text { responden } \\
\% \text { ). }\end{array}$} \\
\hline
\end{tabular}

2. Analisis Bivariat

Tabel 4. Distribusi Frekuensi Anemia Klinis Selama Kehamilan Berdasarkan Usia di Wilayah Kerja Puskesmas Talang Randai Kabupaten Bengkulu Selatan

\begin{tabular}{|c|c|c|c|c|c|c|}
\hline \multirow[b]{2}{*}{ Usia } & & \multicolumn{3}{|c|}{ Kejadian Anemia Klinis } & \multirow[b]{2}{*}{$X^{2}$} & \multirow[b]{2}{*}{$\boldsymbol{P}$} \\
\hline & & Anemia & $\begin{array}{c}\text { Tidak } \\
\text { Anemia }\end{array}$ & Total & & \\
\hline \multirow{2}{*}{ Beresiko } & $\mathrm{n}$ & 24 & 10 & 34 & \multirow{6}{*}{9,702} & \multirow{6}{*}{0,002} \\
\hline & $\%$ & 41,4 & 17,2 & 58,6 & & \\
\hline \multirow{2}{*}{ Tidak beresiko } & $\mathrm{n}$ & 7 & 17 & 24 & & \\
\hline & $\%$ & 12,1 & 29,3 & 41,4 & & \\
\hline \multirow{2}{*}{ Jumlah } & $\mathbf{n}$ & 31 & 27 & 58 & & \\
\hline & $\%$ & 53,4 & 46,6 & 100 & & \\
\hline
\end{tabular}

Hasil analisis hubungan antara usia dengan kejadian anemia klinis selama kehamilan diperoleh bahwa ada sebanyak $24(41,4 \%)$ ibu hamil dengan usia beresiko ( $<20$ dan $>35$ tahun) mengalami anemia, sedangkan diantara ibu hamil yang tidak beresiko ada sebanyak 7 (12,1 $\%)$ yang mengalami anemia. Hasil uji statistic memperlihatkan nilai $\rho=0,002$, maka dapat disimpulkan ada hubungan antara usia dengan kejadian anemia klinis selama kehamilan. 
Tabel 5. Distribusi frekuensi anemia klinis selama kehamilan berdasarkan jarak kehamilan di Wilayah Kerja Puskesmas Talang Randai Kabupaten Bengkulu Selatan

\begin{tabular}{|c|c|c|c|c|c|c|}
\hline \multirow{2}{*}{\multicolumn{2}{|c|}{ Jarak kehamilan }} & \multicolumn{3}{|c|}{ Kejadian Anemia Klinis } & \multirow[b]{2}{*}{$X^{2}$} & \multirow[b]{2}{*}{$\boldsymbol{P}$} \\
\hline & & Anemia & $\begin{array}{c}\text { Tidak } \\
\text { Anemia }\end{array}$ & Total & & \\
\hline \multirow{2}{*}{ Beresiko } & $\mathrm{n}$ & 21 & 8 & 29 & \multirow{6}{*}{8,586} & \multirow{6}{*}{0,003} \\
\hline & $\%$ & 37,5 & 14,3 & 51,8 & & \\
\hline \multirow{2}{*}{ Tidak beresiko } & $\mathrm{n}$ & 9 & 18 & 27 & & \\
\hline & $\%$ & 16,1 & 32,1 & 48,2 & & \\
\hline \multirow{2}{*}{ Jumlah } & $\mathbf{n}$ & 30 & 26 & 56 & & \\
\hline & $\%$ & 53,6 & 46,4 & 100 & & \\
\hline
\end{tabular}

Hasil analisis hubungan antara jarak kehamilan dengan kejadian anemia klinis selama kehamilan diperoleh bahwa ada sebanyak $21(37,5$ $\%)$ ibu hamil dengan jarak kehamilan beresiko $(<2$ tahun) mengalami anemia, sedangkan diantara ibu hamil yang tidak beresiko ada sebanyak 9 (16,1 \%) yang mengalami anemia. Hasil uji statistik memperlihatkan nilai $\rho=0,003$, maka dapat disimpulkan bahwa ada hubungan antara jarak kehamilan dengan kejadian anemia klinis selama kehamilan.

\section{PEMBAHASAN}

\section{Hubungan Usia dengan Kejadian Anemia} Klinis

Berdasarkan data hasil uji statistik usia dengan kejadian anemia klinis maka diperoleh nilai $\rho=0,002$, maka dapat disimpulkan bahwa ada hubungan antara usia dengan kejadian anemia klinis selama kehamilan di Wilayah Kerja Puskesmas Talang Randai Kabupaten Bengkulu Selatan.

Berdasararkan hasil penelitian di Puskesmas Talang Randai Kabupaten Bengkulu Selatan, usia merupakan faktor yang memengaruhi terjadinya anemia pada ibu hamil. Usia ibu yang terlalu muda $(<20$ tahun) dan terlalu tua ( $>35$ tahun) sangat mempengaruhi kejadian anemia selama kehamilan.

Hasil penelitian ini sejalan dengan pendapat Astriana yang menyatakan bahwa usia merupakan faktor risiko yang dapat menyebabkan terjadinya anemia pada kehamilan. Fungsi alat reproduksi wanita yang sehat dan aman untuk hamil adalah pada usia 20 tahun sampai 35 tahun. Apabila seorang wanita hamil pada usia kurang dari 20 tahun maka rentan terjadinya anemia. Hal ini disebabkan pada usia ini fungsi reproduksi belum optimal dan juga pada usia ini emosi dan mental ibu masih labil yang dapat mengakibatkan kurangnya perhatian terhadap pemenuhan kebutuhan gizi selama hamil. Sedangkan ibu hamil diatas usia 35 tahun juga rentan terjadi anemia karena terkait dengan pengaruh dari imunitas atau penurunan daya tahan tubuh sehingga rentan terjadnya penyakit dan mudah terkena infeksi selama hamil (Astriana 2017).

Hasil penelitian ini juga didukug oleh penelitian Yunita yang menyatakan bahwa ibu hamil yang mengalami anemia berada pada umur yang berisiko yaitu usia dibawah 20 tahun dan usia lebih dari 35 tahun (Kedokteran, Katolik, and Mandala 2014).

2. Hubungan jarak kehamilan dengan kejadian anemia klinis

Berdasarkan data hasil uji statistik jarak kehamilan dengan kejadian anemia klinis diperoleh nilai $\rho=0,003$, maka dapat disimpulkan bahwa ada hubungan antara 
jarak kehamilan dengan kejadian anemia klinis selama kehamilan di Wilayah Kerja Puskesmas Talang Randai Kabupaten Bengkulu Selatan.

Berdasarkan hasil penelitian di Puskesmas Talang Randai Kabupaten Bengkulu Selatan, ibu hamil beresiko mengalami anemia yaitu pada kelompok ibu dengan jarak kehamilan yang terlalu dekat atau kurang dari 2 tahun. Hal ini desebabkan karena kondisi ibu belum pulih dari persalinan sebelumnya sehingga menyebabkan menurunnya kesehtan ibu. Kesehatan ibu yang buruk dapat menyebabkan ibu mengalami anemia.

Hasil penelitian ini didukung oleh pendapat Nurhidayat yang menyatakan bahwa ibu hamil dengan jarak kehamilan yang terlalu dekat dapat meyebabkan anemia. Hal ini terjadi karena kondisi ibu yang belum terlalu pulih sehingga pemenuhan kebutuhan asupan zat gizi untuk tubuh ibu kurang optimal. Jika asupan gizi selama hamil tidak mencukupi maka dapat menyebabkan ibu hamil kekurangan energi kronik dan bisa menyebabkan ibu mengalami anemia (Nurhidayati RD 2013).

Hasil penelitian ini juga sejalan dengan penelitian Tanziah, dkk yang menyatakan bahwa ibu hamil yang mempunyai jarak kehamilan kurang dari 2 tahun beresiko 2,3 kali terkena anemia. Jarak kehamilan sangat penting untuk diperhatikan karena jarak kehamilan yang kurang dari 2 tahun dapat mempercepat terjadinya anemia pada ibu hamil (Tanziha, Utama, and Rosmiati 2016).

\section{SIMPULAN DAN SARAN}

\section{A. Simpulan}

1. Sebagian besar kejadian anemia klinis selama kehamilan terjadi pada usia ibu
$<20$ tahun dan $>35$ tahun yaitu sebesar $41,4 \%$.

2. Sebagian besar kejadian anemia klinis selama kehamilan terjadi pada jarak kehamilan $<2$ tahun yaitu sebesar 37,5 $\%$.

3. Ada hubungan antara usia ibu dan jarak kehamilan ibu dengan kejadian anemia klinis selama kehamilan di Wilayah Kerja Puskesmas Talang Randai Kabupaten Bengkulu Selatan.

\section{B. Saran}

1. Bagi Puskesmas

Meningkatkan program dan kinerja petugas kesehatan untuk melakukan upaya penurunan dan mencegah kejadian anemia pada kehamilan.

2. Bagi Ibu Hamil

Diharapkan agar ibu hamil lebih aktif dalam mencari informasi seputar kehamilan, salah satunya informasi tentang anemia yang terjadi selama kehamilan. Informasi tersebut dapat diperoleh dengan memanfaatkan perkembangan teknologi yang ada sekarang seperti jaringan internet, mediamedia masa atau dapat langsung bertanya kepada petugas kesehatan di wilayah setempat.

3. Bagi Peneliti Lain

Agar dapat melakukan penelitian kejadian anemia pada kehamilan dengan variable lainnya.

\section{DAFTAR PUSTAKA}

Astriana, Willy. 2017. "Kejadian Anemia Pada Ibu Hamil Ditinjau Dari Paritas Dan Usia." Jurnal Aisyah: Jurnal Ilmu Kesehatan 2(2):123-30.

DINKES Kabupaten Bengkulu Selatan. 2018. PROFIL KESEHATAN KABUPATEN 
BENGKULU SELATAN. Manna.

Faqih M. 2013. "4 TERLALU 3 TERLAMBAT PENYEBAB NAIKNYA ANGKA KEMATATIAN IBU."

Kedokteran, Fakultas, Universitas Katolik, and Widya Mandala. 2014. "Trimester Iii Di Puskesmas Jagir Surabaya."

Kemenkes RI. 2019. "RAKERNAS STRATEGI PENURUNAN AKI DAN NEONATAL."

Nurhidayati RD. 2013. "Analisis Faktor Penyebab Terjadinya Anemia Pada Ibu Hamil Diwilayah Kerja Puskesmas Tawangsari Kabupaten Sukoharjo." Naskah Publikasi 1-16.
Riskesdas. 2018. "PREVALENSI ANEMIA PADA IBU HAMIL."

Saifuddin AB. 2011. BUKU ACUAN NASIONAL PELAYANAN KESEHATAN MATERNAL DAN NEONATAL.

Setiawati, Sumini, Rilyani, Riska Wandinii, Aryanti Wardiah, and Lidya Aryanti. 2014. "Faktor-Faktor Yang Mempengaruhi Kejadian Anemia Pada Ibu Hamil Di Wilayah Kerja Puskesmas Sekampung Kabupaten Lampung Timur Tahun 2013." Jurnal Kesehatan Holistik 8(2):53-58.

Tanziha, Ikeu, Lalu Juntra Utama, and Risti Rosmiati. 2016. "Faktor Risiko Anemia Ibu Hamil Di Indonesia.” 11(2):143-52. 